\title{
CUBA: ARQUEOLOGÍA Y LEGADO HISTÓRICO, EDICIONES POLYMITA SA. CIUDAD DE GUATEMALA, 2018, 230 PÁGS., ISBN: 9929667164
}

\author{
Jorge Ulloa Hung \\ Instituto Tecnológico de Santo Domingo (INTEC), República Dominicana. \\ ORCID: 0000-0002-2680-1530, Correo-e: jorge.ulloa@intec.edu.do
}

Cómo citar: Ulloa Hung, J. (2021). Cuba: Arqueología y Legado Histórico, Ediciones Polymita SA. Ciudad de Guatemala, 2018, 230 págs., ISBN: 9929 667164. Ciencia y Sociedad, 46(1), 73-76. https://doi.org/10.22206/cys.2021.v46i1.pp73-76

Los estudios sobre el patrimonio y su trascendencia para las historias y culturas del Caribe han cobrado mayor auge en las últimas décadas. Estos han ganado en diversidad de temas (Carrasquillo, 2018; Jean, Sonnemann \& Hofman, 2021; Siegel \& Righter, 2011; Timothy \& Nyaupane, 2009), además de proliferar estudios con enfoques multidisciplinarios ligados a las importantes transformaciones y aperturas experimentadas por las Ciencias Sociales (Hofman, Ulloa Hung, Herrera Malatesta, Jean, Sonnemann \& Hoogland, 2018; Hofman \& Ulloa Hung, 2019).

En la arqueología del Caribe, algunas de las expresiones más relevantes de ese fenómeno comprenden los estudios relacionados con las diversas amenazas que actualmente gravitan sobre el patrimonio cultural (Ezcurra \& Rivera Collazo, 2018; Jean, Marc, Camille \& Michel, 2020; Rodríguez Rosales et al., 2021; Siegel et al., 2013) así como los estudios con un enfoque descolonizador (Hofman et al., 2020; Pesoutova, 2019; Ulloa Hung \&Valcárcel Rojas, 2016; Valcárcel Rojas \& Ulloa Hung, 2018) con el objetivo de reivindicar legados de actores sociales marginados u obnubilados en los llamados patrimonios nacionales. Es precisamente dentro de esta tendencia encauzada por la multidisciplinariedad

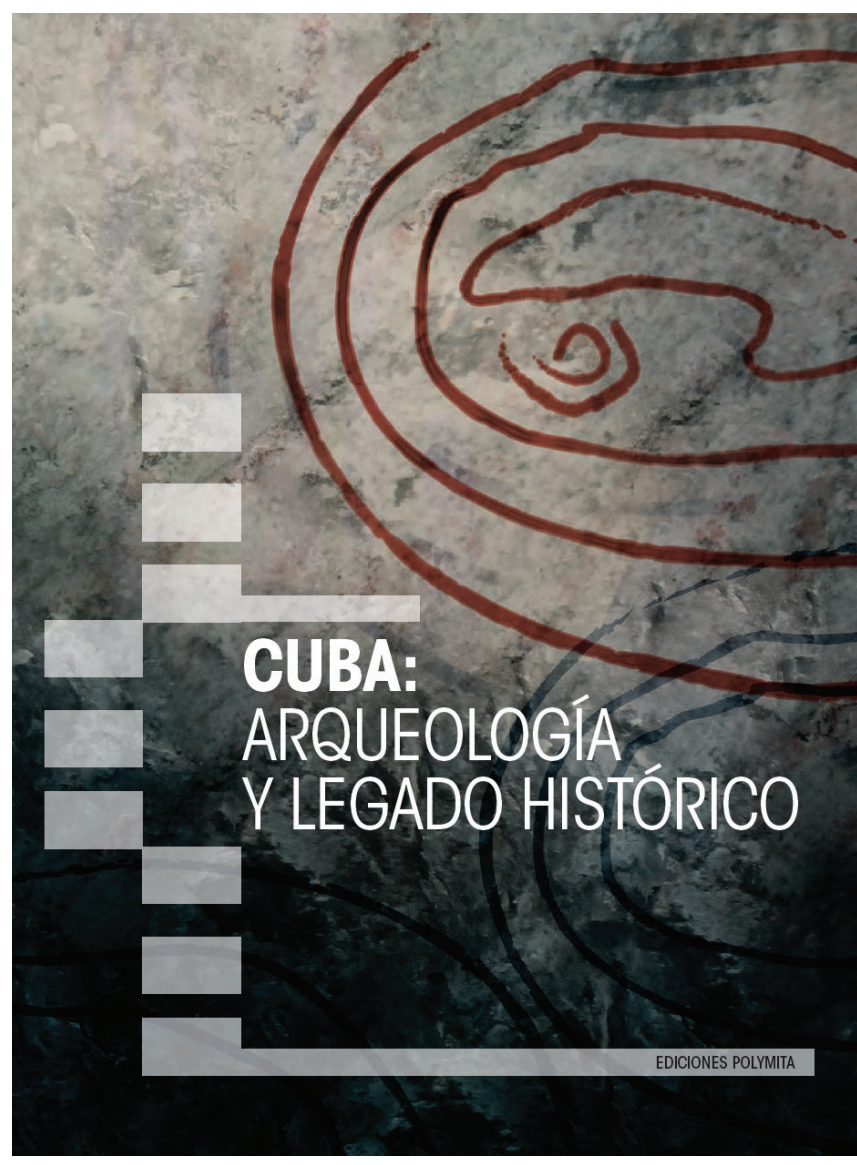

Esta obra es de acceso abierto y los interesados pueden descargar la misma a través del siguiente link: http://cubaarqueologica. org/\#!/-biblioteca/ 
y el reconocimiento de la diversidad en la que se inscribe Cuba: Arqueología y legado histórico.

Integrada por un colectivo de autores cuyas contribuciones se alinean a lo largo de 22 capitulos, editada por Armando Rangel Rivero, y prologo de José Barreiro, Cuba: Arqueología y Legado Histórico ofrece una perspectiva diversa y actualizada de la investigación arqueológica en Cuba. A través de sus páginas resalta el potencial de esa disciplina científica para comprender el pasado y, a su vez, reivindicar a los creadores y portadores de un legado histórico, generalmente marginado dentro de las narrativas históricas y de los estudios culturales.

La obra compila estudios orientados a comprender el pasado indígena desde componentes de la cultura material presente en los registros arqueológicos, pero también a partir de aspectos de composición genética, lingüística, crítica histórica, manifestaciones estéticas, elementos sociales, curativos, relaciones con la flora y la fauna, entre otros. Desde esa perspectiva, el legado histórico de los primeros habitantes de la isla es analizado a partir de datos e informaciones que resaltan por su diversidad y el intento de abarcar diferentes aspectos dentro del tema. Esta característica, le atribuye un enfoque integral y cierto carácter holístico que escapa de las visiones tradicionalmente asumidas por los estudios y compilaciones sobre legados indígenas. En ese orden, resalta el recorrido por los inicios del interés arqueológico en Cuba hasta adentrarse en aspectos relevantes de la arqueología cubana contemporánea con un amplio y necesario sentido de síntesis.

La estructura de la obra permite discernir tres momentos relevantes en su narrativa. Esos momentos perfilan un recorrido que va de lo general a lo particular, y que inicia con amplias sistematizaciones sobre las comunidades aborígenes cubanas donde los análisis historiográficos, los datos etnológicos y arqueológicos se entrelazan con informaciones de otras disciplinas para generar un cuadro general y abarcador de estas poblaciones.
Un segundo momento contempla estudios de cultura material asociada a los registros arqueológicos o sitios arqueológicos excepcionales. Útiles y herramientas de madera, concha y lítica entre los aborígenes cubanos, y sitios como Los Buchillones y el Chorro de Maita, constituyen los protagonistas de un conjunto de contribuciones donde el enfoque propiamente arqueológico adquiere mayor relevancia. El tercer momento dentro de la estructura narrativa revela segmentos de un legado indígena entronizado en la sociedad cubana contemporánea, especialmente en su composición genética, lingüística y cultural. Un aspecto relevante de esta sección, y de la obra en general, es el hecho de abordar legados históricos y patrimoniales ajenos a la monumentalidad colonial, esta última sobrestimada o ampliamente distinguida al exaltar los valores patrimoniales en la mayor parte de las naciones del Caribe.

Cuba: Arqueología y legado histórico constituye un resumen y sistematización de algunos de los estudios y resultados más recientes de la arqueología cubana, relevantes no solo para el espacio de esa isla, sino también para toda la región del Caribe. Este aspecto le atribuye un carácter abiertamente didáctico y académico para la enseñanza de la Antropología, la Arqueología y las Ciencias Sociales en general. Elemento que se complementa con el hecho de estar escrita en lenguaje abierto, asequible a un público no especializado, y un amplio nivel de ilustración con imágenes a color que complementan el texto $\mathrm{y}$ refuerzan esos valores.

La obra también revela elementos en los que la arqueología cubana mantiene abierta discusión, y que evidentemente precisan mayor atención e investigaciones en aras de trascender antiguos modelos de comprensión e interpretación. Especialmente, algunos de los datos expuestos en esta obra resaltan la necesidad de discutir esos modelos de comprensión a partir de una mayor complejidad y diversidad de enfoques. En ese reglón sobresalen aspectos como las clasificaciones de las comunidades indígenas, el uso de conceptos y categorías de análisis que aún 


\section{Cuba: Arqueología y Legado Histórico, Ediciones Polymita SA. Ciudad de Guatemala, 2018, 230 págs., ISBN: 9929667164}

precisan mayor sostén empírico. En ese mismo orden, a pesar de constituir una obra sobre arqueología y legado histórico, se echa de menos contribuciones de la arqueología histórica en Cuba, la que a pesar de ser más joven que la arqueología sobre temas indígenas, en las últimas décadas ha logrado avances en el reconocimiento de indígenas y africanos en sus disímiles procesos de adaptación a la sociedad colonial en Cuba. Incluir ese aspecto contribuiría a contrarrestar las propias ideas de temprana desaparición de las comunidades indígenas y documentar la diversidad de formas y mecanismos de agencia utilizados por esas poblaciones para adaptarse, sobrevivir o resistir la sociedad colonial. Aspectos que son vitales para comprender o considerar lo que precisamente se están considerado como algunos de sus legados históricos.

En síntesis, Cuba: Arqueología y legado histórico tiene la capacidad de mostrar, en perspectiva y con amplio poder de síntesis, el esfuerzo desplegado por la arqueología en Cuba en aras de registrar, conservar y estudiar el patrimonio relacionado con sus comunidades originarias. Esfuerzos, como bien muestra la obra, imprescindibles para desentrañar las incidencias de un patrimonio y un legado cultural que es vital, si realmente deseamos una comprensión histórica más holística y compleja del actual tejido social y étnico de Cuba y el Caribe.

\section{Referencias}

Carrasquillo, R. E. (2018). Primicias de Santo Domingo. Ruinas históricas, patrimonio cultural y sus significados entre los dominicanos de hoy. Americana. Revista de Estudios Latinoamericanos, 8, 225-256.

Ezcurra, P., \& Rivera-Collazo, I. C. (2018). An assessment of the impacts of climate change on Puerto Rico's Cultural Heritage with a case study on sea-level rise. Journal of Cultural Heritage, 32, 198-209. Disponible en https://doi. org/10.1016/j.culher.2018.01.016
Hofman, C. L., \& Ulloa Hung, J. (2019). NEXUS 1492: Encuentros del Nuevo Mundo con un mundo en globalización. Ciencia y Sociedad, 44(4), 95-115. Disponible en https://doi. org/10.22206/cys.2019.v44i4.pp95-115

Hofman, C. L., Ulloa Hung, J, Herrera Malatesta, E., Jean, J. S., Sonnemann, T., \& Hoogland, M. (2018). Indigenous Caribbean perspectives: archaeologies and legacies of the first colonised region in the New World. Antiquity, 92(361), 200-216. Disponible en https://doi. org/10.15184/aqy.2017.247

Hofman, C.L; Valcarcel Rojas, R and Ulloa Hung, J. (2020). Colonization, Transformation, and Indigenous Cultural Persistence in the Caribbean. In Christine D. Beaule and John G. Douglass (Ed.), The Global Spanish Empire. Five hundred years of place making and pluralism (pp. 55-82). Tucson: University of Arizona Press.

Jean, J. S., Marc, J., Camille, C. \& Michel, J. (2020). Haitian Archaeological Heritage: Understanding Its Loss and Paths to Future Preservation, Heritage 3, 733-752.

Jean, J. S., Sonnemann, T., \& Hofman, C. L. (2021). Complex landscape biographies: palimpsests of Complex landscape biographies: palimpsests of Fort-Liberté, Haití. Landscape Research, OO(00), 1-20. Disponible en https://doi.org/1 $0.1080 / 01426397.2020 .1871472$

Pesoutova, J. (2019). Indigenous ancestors and healing landscapes: Cultural memory and intercultural communication in the Dominican Republic and Cuba. Leiden: Sidestone Press.

Rodríguez-Rosales, B., Abreu, D., Ortiz, R., Becerra, J., Cepero-Acán, A. E., Vázquez, M. A. \& Ortiz, P. (2021). Risk and vulnerability assessment in coastal environments applied to heritage buildings in Havana (Cuba) and Cadiz (Spain). Science of the Total Environment, 750. Disponible en https://doi.org/10.1016/j.scitotenv.2020.141617 
Siegel, P. E., Hofman, C. L., Bérard, B., Murphy, R., Ulloa Hung, J., Valcárcel Rojas, R. \& White, C. (2013). Confronting Caribbean heritage in an archipelago of diversity: Politics, stakeholders, climate change, natural disasters, tourism, and development. Journal of field archaeology, 38(4), 376-390.

Siegel, P. E. \& Righter, E. (Eds.) (2011). Protecting Heritage in the Caribbean. Tuscaloosa: University of Alabama Press.

Timothy, D. J., \& Nyaupane, G. P. (Eds.). (2009). Cultural heritage and tourism in the developing world: A regional perspective. Routledge.
Ulloa Hung, J. \& Valcarcel Rojas, R. (2016). Indigenas e Indios en el Caribe. Presencia, legado y estudio. Santo Domingo: Instituto Tecnológico de Santo Domingo.

Valcárcel Rojas, R. \& Ulloa Hung, J. (Eds.). (2018). De la desaparición a la permanencia: indigenas $e$ indios en la reinvención del Caribe. Santo Domingo: Instituto Tecnológico de Santo Domingo y Fundación García Arévalo. 